\title{
Pattern of Organophosphorous Poisoning: A Retrospective Community Based Study
}

\author{
Chataut J, Adhikari RK, Sinha NP, Marahatta SB
}

Department of Community Medicine

Kathmandu University School of Medical Sciences

Dhulikhel, Kavre, Nepal.

Corresponding Author

Jagadish Chataut

Department of Community Medicine

Kathmandu University School of Medical Sciences

Dhulikhel, Kavre, Nepal.

Email: jagadish_chataut@yahoo.com

Citation

Chataut J, Adhikari RK, Sinha NP, Marahatta SB.

Pattern of organophosphorous poisoning: a

retrospective community based study. Kathmandu Univ Med J 2011;34(2)31-4.

\begin{abstract}
Background

Pesticide poisoning is very common in Nepal. Hospital based studies from various parts of Nepal have shown that poisoning with organophosphorus compounds is the most common type of poisoning. Current study is undertaken to see the pattern of organophosphorus poisoning and to identify the common risk factors among the cases. If the risk factors are modifiable, attempts in addressing the risk factors and decreasing the likelihood of poisoning will certainly be fruitful in reducing the morbidity and mortality associated with organophosphorus poisoning.
\end{abstract}

\section{Objectives}

To assess the risk factors of organophosphorus poisoning which is major public health problem in Nepal.

\section{Methods}

A community based retrospective study of 75 cases of organophosphate poisoning who were brought to the emergency department of Dhulikhel hospital over the period of 3 years. Basic information was collected from hospital records and home visits were made to study the risk factors. Data were collected through interviews of the study population and their family members using a pre-designed questionnaire.

\section{Results}

In this study 75 cases and their families were interviewed of which there were 59\% males and $42 \%$ females (M/F ratio of $1: 1.4)$. The majority (40\%) of the poisoning cases were in the age group 25-34 years. Lower literacy level showed positive association with the incidence of poisoning. Occupation wise vast majority (80\%) of the cases were engaged in agricultural work. Suicidal attempts by ingesting organophosphate compounds were high in farmers and females.

\section{Conclusion}

In this study, majority of the poisoning were attempts of intentional self harm. Agriculture workers and females are high risk groups and may be associated with the fact that they have easy access to the poison. Interventions directed towards health education, counseling, and enforcement of laws restricting the availability and use of harmful pesticides may help in reducing such events in future.

\section{KEY WORDS}

Organophosphorus, Pesticides.

\section{INTRODUCTION}

The World Health Organization estimated that there were 873,000 suicides worldwide in 2002 which make suicide a major cause of premature mortality globally. ${ }^{1}$ It is therefore important to identify the most commonly used methods of suicide to design appropriate strategies for restricting access to such methods and to improve the ability of health care systems to effectively treat individuals who use these methods.

The WHO reports that pesticides are now the most common method of suicide worldwide. ${ }^{2}$ Acute poisoning with organophosphorous agents is a major clinical problem globally, with thousands of deaths occurring every year. ${ }^{3}$ Most of these pesticide poisoning and subsequent deaths occur in developing countries following a deliberate self ingestion of the poison.

Poisoning has been a common cause of medical admissions and deaths in Nepalese hospitals. ${ }^{4-8}$ Hospital based studies from five major hospitals in Nepal in 1999 - 2000 showed that OP compounds were the most common form of poisoning comprising $52 \%$ of total cases. ${ }^{9}$ Various isolated hospital-based studies also clearly demonstrate that OP 
compounds occupy the greatest burden of poisoning related morbidity and mortality in Nepal. ${ }^{8}$

Metacid- also known as Methyl parathion is the most commonly ingested OP pesticide. OP poisoning is an important preventable public health problem in developing countries. Though accidental poisoning can occur following exposure or inhalation, serious poisoning often follows suicidal ingestion. ${ }^{10}$ There are various hospital based studies available on poisoning but this is a community based study where we have tried to assess the risk factors of pesticide poisoning by home visits and collected the information by personal interviews of cases.

\section{METHODS}

Of all 90 cases of organophosphorus poisoning that were brought to the Emergency department of Dhulikhel Hospital, a Kathmandu University Hospital, Kavre, during the period from June 2006 to June 2009, 75 could be traced and were interviewed in this community based retrospective study.

The basic information was obtained from hospital records and subsequent home visits were made. The cases and family were interviewed with the help of detailed questionnaire which included information on demographic characteristics viz. age, sex, marital status, religion, caste, education, occupation and socio economic status and the reasons for the poisoning. The purpose of visit was explained to the cases and their family members and their co-operation sought in the form of verbal consent. The Statistical Package for Social Sciences (SPSS) version 11.5 for windows was used to analyze the data.

\section{RESULTS}

The distribution of the cases with regards to their socio demographic characteristics is presented in Table 1 . Out of 75 cases $58.7 \%$ (44) consisted of women with male to female ratio of $1: 1.4$. According to the age distribution $40 \%$ (30) of the cases were $25-34$ years old followed by $29 \%$ (22)

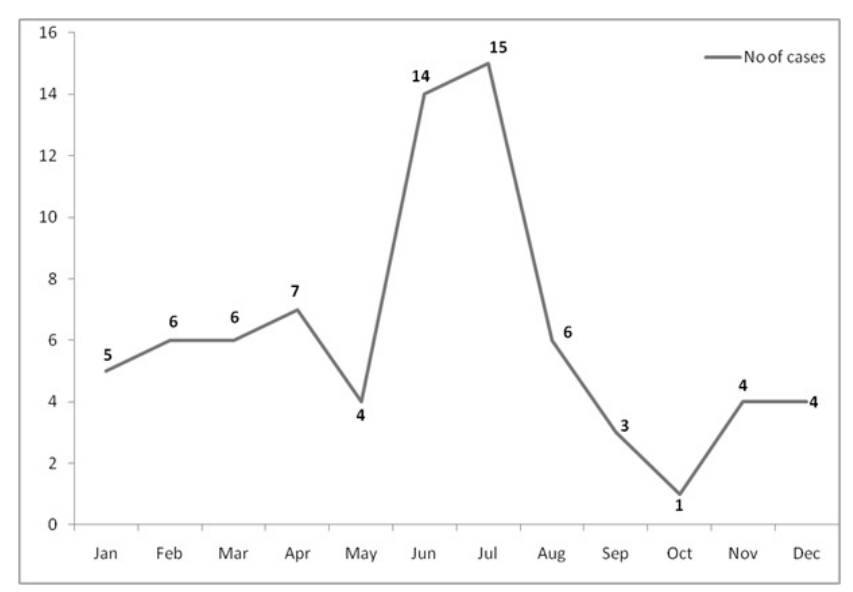

Figure 1. Seasonal Distribution of the cases $(n=75)$.

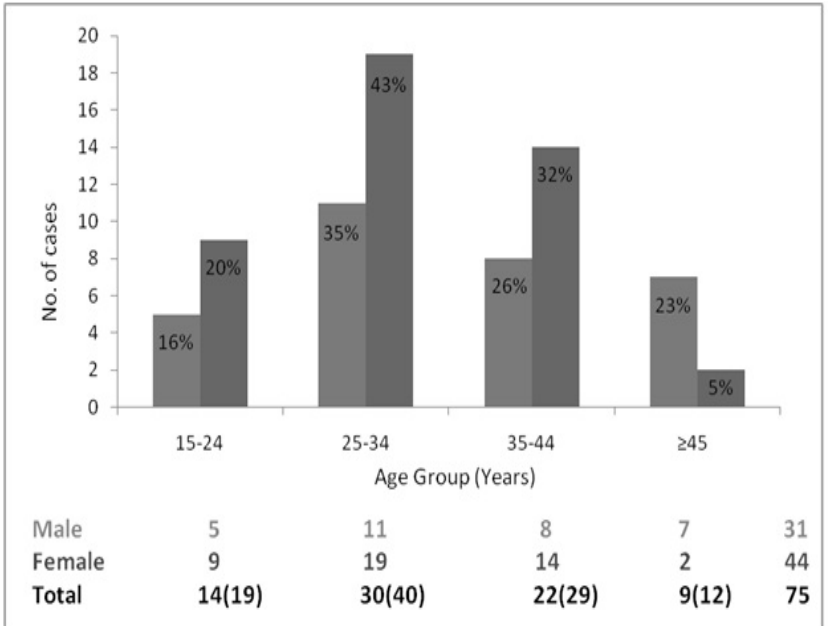

Figure 2. Distribution of cases according to age and sex.

35-44 years old as shown in Fig 2. The distribution of the cases with regards to their ages clearly shows that majority of the cases fall under the productive age group. Poisoning cases were high in Newar community 28\% (21) followed by Magar's 24\% (18). Incidence of poisoning was seen higher among the people who had a lower level of education. A majority (80\%) of the total cases were involved in agriculture as their primary occupation.

The monthly breakdown of all the 75 cases of OP poisoning is depicted in Fig 1. Majority of the cases (52\%) fall in between the months of May and August; the months between May and August is the rainy season in Nepal. Of all the cases, 39\% (29) cases fall in the months of June and July alone; June and July are often considered the most suitable months for farming.

Table 1. Socio demographic characteristics of the OP cases $(n=75)$

\begin{tabular}{|ll|}
\hline GENDER & NUMBER (\%) \\
\hline Male & $31(41.3)$ \\
\hline Female & $44(58.7)$ \\
\hline ETHNICITY & NUMBER (\%) \\
\hline Brahmin & $6(8.0)$ \\
\hline Chhetri & $10(13.4)$ \\
\hline Newar & $21(28.0)$ \\
\hline Gurung & $7(9.3)$ \\
\hline Magar & $18(24.0)$ \\
\hline Tamang & $13(17.3)$ \\
\hline LITERACY & NUMBER (\%) \\
\hline Graduate \& Above & $1(1.3)$ \\
\hline High Secondary & $3(4.0)$ \\
\hline Secondary & $23(30.7)$ \\
\hline Primary & $29(38.7)$ \\
\hline Illiterate & $19(25.3)$ \\
\hline OgCCPATION & $60(80.0)$ \\
\hline Non- agriculture & 15 (20.0) \\
\hline
\end{tabular}


Table 2. Factors responsible for OP poisoning.

\begin{tabular}{|llll|}
\hline Cause of poisoning & Male & Female & Total (\%) \\
\hline Financial problems & 9 & 6 & $15(20.0)$ \\
\hline Domestic troubles & 5 & 8 & $13(17.3)$ \\
\hline Unsuccessful love affairs & 5 & 7 & $12(16.0)$ \\
\hline Marital disharmony & 3 & 7 & $10(13.3)$ \\
\hline Domestic violence & 1 & 7 & $8(10.6)$ \\
\hline Dowry problem & 1 & 4 & $5(6.7)$ \\
\hline Prolonged illness & 3 & 2 & $5(6.7)$ \\
\hline Loss of job/employment & 2 & 1 & $3(4.0)$ \\
\hline Accidental ingestion & 2 & 0 & $2(2.7)$ \\
\hline Mental disorder & 0 & 2 & $2(2.7)$ \\
\hline Total & 31 & 44 & 75 \\
\hline
\end{tabular}

Table 2 shows that $97 \%$ (73) of all the cases were from suicidal acts. A majority of the cases (20\%) were due to financial problems, which is followed by domestic troubles (17.3\%), unsuccessful love affairs (16\%), and marital disharmony (13\%). The rest were because of variety of reasons like domestic violence, dowry problem, chronic illness, and loss of job. Accidental ingestion was reported in only two cases.

\section{DISCUSSION}

Deliberate self-poisoning with pesticides is a major problem in the developing world; it is the cause of many deaths, particularly among young people. WHO estimates that three million cases of pesticide poisoning occur worldwide every year, with 220000 deaths, most of which are intentional. ${ }^{11}$ In the present time, because of the easy and unrestricted availability, insecticides especially organophosphorous compounds, have become the easiest and tool of choice for suicidal attempts. 75 cases of OP poisoning were retrospectively studied in this community based study. Our study reveals the predominance of females in OP poisoning with overall male to female ratio of 1:1.4. Many such findings where number of females exceeded the males were observed in various studies across the country. ${ }^{4,6,8,9,12-15}$ These findings contradict from the study done in South Indian population by Srinivas Rao et al, which reported that poisoning with pesticides in males outnumbered that in females (57\% vs. $43 \%){ }^{16}$

Majorities (59\%) of the total cases fall in the age group less than 35 years of age. It may be explained with the fact that they are the ones with the main responsibilities of the family and may be under constant stress and also they are more exposed to OP compounds. Several other studies also indicate that people of productive age group are more vulnerable to poisoning which easily makes them high risk group. Singh DP et al in their study of OP poisoning conducted in Bir hospital found that $76.8 \%$ of the female cases and $46.5 \%$ of the male cases were from the age group of 16 to 25 years old. ${ }^{12}$ Similarly, Karki $P$ et al in their study in eastern Nepal found that the majority (65\%) of the OP poisoning patients were in the 15 to 30 years age group. ${ }^{15}$ Study of Srinivas Rao et al from South Indian hospital also reveals that the two thirds of OP poisoning cases were aged less than 30 years of age. ${ }^{16}$

About $97 \%$ of cases in the present study were acts of intentional self-poisoning; this finding can be matched with the findings of a study done in Bir hospital by Singh DP et al (98\%), a study done by Srinivas Rao et al from South Indian hospital (96\%), Kar SM et al (95\%) and Karki P et al in their study found intentional self harm to be $89 \%$. $^{12,13,15,16}$ These findings are quite contrast to the findings of the study done by Khadka SB et al where intentional self harm was just $58 \% .{ }^{14}$ Causes of self harm were because of variety of reasons financial problem, domestic troubles, unsuccessful love, marital disharmony, chronic illness and loss of job.

Distribution of cases according to the season shows that more than half the cases (52\%) fall in between the months of May and August; this finding is comparable to the finding of a study, done in Pokhara by Kar SM et al, which reported that $57 \%$ of the cases fall in the months between May and August. ${ }^{13}$ High incidence in these months may be because of the fact that these are the months when people are engaged in farming and the insecticides are easily available. Fig. 1 reveals that cases decrease drastically in the months of September and October; this could be because of the arrival of the festive season.

\section{CONCLUSION}

At present, pesticides remain an integral part of agricultural activities in our country hence pesticide poisoning is very common in Nepal and organophosphorus is one of the most common poisons consumed because of its wide and easy availability. In this study majority of the poisoning was intentional self harm because of wide range of reasons such as financial problem, domestic troubles, unsuccessful love affairs, marital disharmony, chronic illness, and loss of job. Findings from this study suggest that interventions are warranted to prevent such events and unnecessary loss of lives in the future. Possible interventions could be strict law regarding the sale of such compounds, improved storage which will reduce the easy accessibility during the time of stress, health education, and counseling which would develop their skill to cope with the problems and improvement of the socio economic status of the people.

\section{REFERENCES}

1. World Health Report 2004. WHO, Geneva; 2004.

2. Bertolote JM, Fleischmann A, Butchart A, Besbelli N: Suicide, suicide attempts and pesticides: a major hidden public health problem. Bull World Health Organ 2006, 84:260.

3. Eddleston M, Buckley NA, Checketts H, Senarathna L, Mohamed F, Rezvi Sheriff MH et al. Speed of Initial Atropinization in Significant Organophosphorous Pesticide Poisoning- A Systematic Comparison of Recommended Regimens. J Toxicol Clin Toxicol 2004; 42:865-75. 
Table 2. Factors responsible for OP poisoning.

\begin{tabular}{|llll|}
\hline Cause of poisoning & Male & Female & Total (\%) \\
\hline Financial problems & 9 & 6 & $15(20.0)$ \\
\hline Domestic troubles & 5 & 8 & $13(17.3)$ \\
\hline Unsuccessful love affairs & 5 & 7 & $12(16.0)$ \\
\hline Marital disharmony & 3 & 7 & $10(13.3)$ \\
\hline Domestic violence & 1 & 7 & $8(10.6)$ \\
\hline Dowry problem & 1 & 4 & $5(6.7)$ \\
\hline Prolonged illness & 3 & 2 & $5(6.7)$ \\
\hline Loss of job/employment & 2 & 1 & $3(4.0)$ \\
\hline Accidental ingestion & 2 & 0 & $2(2.7)$ \\
\hline Mental disorder & 0 & 2 & $2(2.7)$ \\
\hline Total & 31 & 44 & 75 \\
\hline
\end{tabular}

Table 2 shows that $97 \%$ (73) of all the cases were from suicidal acts. A majority of the cases (20\%) were due to financial problems, which is followed by domestic troubles (17.3\%), unsuccessful love affairs (16\%), and marital disharmony (13\%). The rest were because of variety of reasons like domestic violence, dowry problem, chronic illness, and loss of job. Accidental ingestion was reported in only two cases.

\section{DISCUSSION}

Deliberate self-poisoning with pesticides is a major problem in the developing world; it is the cause of many deaths, particularly among young people. WHO estimates that three million cases of pesticide poisoning occur worldwide every year, with 220000 deaths, most of which are intentional. ${ }^{11}$ In the present time, because of the easy and unrestricted availability, insecticides especially organophosphorous compounds, have become the easiest and tool of choice for suicidal attempts. 75 cases of OP poisoning were retrospectively studied in this community based study. Our study reveals the predominance of females in OP poisoning with overall male to female ratio of 1:1.4. Many such findings where number of females exceeded the males were observed in various studies across the country. ${ }^{4,6,8,9,12-15}$ These findings contradict from the study done in South Indian population by Srinivas Rao et al, which reported that poisoning with pesticides in males outnumbered that in females (57\% vs. $43 \%){ }^{16}$

Majorities (59\%) of the total cases fall in the age group less than 35 years of age. It may be explained with the fact that they are the ones with the main responsibilities of the family and may be under constant stress and also they are more exposed to OP compounds. Several other studies also indicate that people of productive age group are more vulnerable to poisoning which easily makes them high risk group. Singh DP et al in their study of OP poisoning conducted in Bir hospital found that $76.8 \%$ of the female cases and $46.5 \%$ of the male cases were from the age group of 16 to 25 years old. ${ }^{12}$ Similarly, Karki $P$ et al in their study in eastern Nepal found that the majority (65\%) of the OP poisoning patients were in the 15 to 30 years age group. ${ }^{15}$ Study of Srinivas Rao et al from South Indian hospital also reveals that the two thirds of OP poisoning cases were aged less than 30 years of age. ${ }^{16}$

About $97 \%$ of cases in the present study were acts of intentional self-poisoning; this finding can be matched with the findings of a study done in Bir hospital by Singh DP et al (98\%), a study done by Srinivas Rao et al from South Indian hospital (96\%), Kar SM et al (95\%) and Karki P et al in their study found intentional self harm to be $89 \%$. $^{12,13,15,16}$ These findings are quite contrast to the findings of the study done by Khadka SB et al where intentional self harm was just $58 \% .{ }^{14}$ Causes of self harm were because of variety of reasons financial problem, domestic troubles, unsuccessful love, marital disharmony, chronic illness and loss of job.

Distribution of cases according to the season shows that more than half the cases (52\%) fall in between the months of May and August; this finding is comparable to the finding of a study, done in Pokhara by Kar SM et al, which reported that $57 \%$ of the cases fall in the months between May and August. ${ }^{13}$ High incidence in these months may be because of the fact that these are the months when people are engaged in farming and the insecticides are easily available. Fig. 1 reveals that cases decrease drastically in the months of September and October; this could be because of the arrival of the festive season.

\section{CONCLUSION}

At present, pesticides remain an integral part of agricultural activities in our country hence pesticide poisoning is very common in Nepal and organophosphorus is one of the most common poisons consumed because of its wide and easy availability. In this study majority of the poisoning was intentional self harm because of wide range of reasons such as financial problem, domestic troubles, unsuccessful love affairs, marital disharmony, chronic illness, and loss of job. Findings from this study suggest that interventions are warranted to prevent such events and unnecessary loss of lives in the future. Possible interventions could be strict law regarding the sale of such compounds, improved storage which will reduce the easy accessibility during the time of stress, health education, and counseling which would develop their skill to cope with the problems and improvement of the socio economic status of the people.

\section{REFERENCES}

1. World Health Report 2004. WHO, Geneva; 2004.

2. Bertolote JM, Fleischmann A, Butchart A, Besbelli N: Suicide, suicide attempts and pesticides: a major hidden public health problem. Bull World Health Organ 2006, 84:260.

3. Eddleston M, Buckley NA, Checketts H, Senarathna L, Mohamed F, Rezvi Sheriff MH et al. Speed of Initial Atropinization in Significant Organophosphorous Pesticide Poisoning- A Systematic Comparison of Recommended Regimens. J Toxicol Clin Toxicol 2004; 42:865-75. 
4. Kafle KK, Gyawali KK. Organophosphorus- Commonest Poisoning Agent. J Inst Med 1992; 14: 228-33.

5. Prasad PN, Karki P. Poisoning cases at TUTH emergency; a one-year review. J Inst Med 1997; 19: 18-24.

6. Rauniyar GP, Das BP, Naga Rani MA, Gupta MP, Karki BMS. Retrospective Analysis of Profile of Acute Poisoning Cases in a Tertiary Care Hospital in Eastern Nepal: A Four-Year Database from 1994 to 1997. J Nep Med Assoc 1999; 38: 23-8.

7. Pathak UN, Chhetri PK, Dhungel S, Chokhani R, Devkota KC, Shrestha $\mathrm{BO}$ et al. Retrospective Study of Poisoning Cases Admitted in Nepal Medical College Teaching Hospital. Nep Med Col J 2001; 3: 101-5.

8. Paudyal BP. Poisoning: Pattern and Profile of Admitted Cases in a Hospital in Central Nepal. J Nep Med Assoc 2005; 44:92-6.

9. Gupta SK, Joshi MP. Pesticide Poisoning Cases Attending Five Major Hospitals of Nepal. J Nep Med Assoc 2002; 41:447-56.

10. Dutoit PW, Maller FO, Ventonder WM, Ungerer MJ. Experience with intensive care management of organophosphate insecticide poisoning. S Afr Med J 1981; 60:227-9.
11. WHO in collaboration with UNEP. Public health impact of pesticides used in agriculture. Geneva: World Health Organization, 1990.

12. Singh DP, Aacharya RP. Pattern of poisoning cases in Bir Hospital. J Inst Med 2006; 28:1: 3-6.

13. Kar SM, Timsinha S, Agrawal P. An Epidemiological study of Organophosphorus Poisoning at Manipal Teaching Hospital, Pokhara, Nepal. J Indian Acad Forensic Med 32(2): 108-9.

14. Khadka SB, Ale SB. A study of poisoning cases in emergency Kathmandu Medical College Teaching Hospital. Kathmandu Univ Med J 2005; 3: 388-91.

15. Karki P, Ansari JA, Bhandary S, Koirala S. Cardiac and electrocardiographical manifestations of acute organophosphate poisoning. Singapore Med J 2004;45:385-9.

16. Srinivas Rao CH, Venkateswarlu V, Surender T, Eddleston M, Buckley NA. Pesticide Poisoning in South India - Opportunities for Prevention and Improved Medical Management. Trop Med Int Health 2005 June; 10(6): 581-8. 